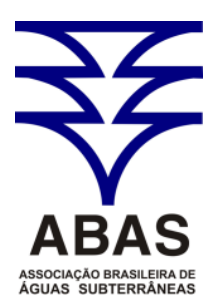

www.abas.org

\section{COMPORTAMENTO DE ÍONS DE METAIS PESADOS (Pb E Ni) E DE COMPOSTOS NITROGENADOS EM ÁREA INDUSTRIAL IMPACTADA NO MUNICÍPIO DE CUBATÃO-SP}

\author{
HEAVY METALS (Pb AND Ni) AND NITROGENOUS COMPOUNDS \\ BEHAVIOR IN AN IMPACTED INDUSTRIAL AREA IN THE DISTRICT OF \\ CUBATÃO-SP
}

Robercal Asevedo Berrocal ${ }^{1}$; Raphael Hypolito ${ }^{2}$; Sibele Ezaki ${ }^{3}$

\begin{abstract}
In an industrial area of intense activity, located in Cubatão (SP), great quantities of undergrounded residuals and materials of high concentrations of organic and ionic nature were discharged. It was detected contamination in the ground waters of three areas (B, C, and D) with lead and nickel ions overtaking CETESB standard values. Due to this high content owing to the industrial activities, it was also detected the presence of $\mathrm{Al}^{3+}$ and $\mathrm{Fe}^{3+}$ in the aqueous solution, as $\mathrm{Al}(\mathrm{OH})_{3}$ and $\mathrm{Fe}(\mathrm{OH})_{3}$ and colloidal forms. In a larger portion of the study area ammonia $\left(\mathrm{NH}_{3}\right)$ was indentified in groundwater in concentrations higher than the limit established by Portaria 518 (Health Ministry). In wells localized in Areas B and C, nitrate presented higher values them than the limit established by CETESB. Mean hydraulic conductivity in the area is $4,70 \times 10^{-4} \mathrm{~cm} / \mathrm{s}$. A mathematical model was elaborated by interpolating hydraulic conductivity and chemical analyses data, and defining the main underground that flows to the west, towards the Perequê River. The model results suggest that the water flow with ammonia concentration larger than the allowed standard, from the aquifer to the river tends to decline until extinction in a 10 years period. Considering the present plum dimension and the observed concentration levels, the modeling indicated that plum with the concentrations larger than the allowed limit will be not extinct in 20 years (the end of the simulated period).
\end{abstract}

Keywords: Groundwater. Contamination. Nitrogenized Compounds. Heavy Metal Ions.

Resumo: Em uma área de intensa atividade industrial, localizada no Município de Cubatão (SP), foi descartada grande quantidade de resíduos e materiais com elevados teores de substâncias poluentes de naturezas orgânicas e inorgânicas. Foram constatadas em três subáreas (B, C e D), contaminações das águas subterrâneas com íons chumbo e níquel que ultrapassaram os valores orientadores da CETESB. Devido ao elevado conteúdo iônico associado às atividades industriais constatou-se também a presença de $\mathrm{Al}^{3+} \mathrm{e} \mathrm{Fe}^{3+}$ em solução aquosa, precipitados como $\mathrm{Al}(\mathrm{OH})_{3}$ e $\mathrm{Fe}(\mathrm{OH})_{3}$ e na forma coloidal. Em boa parte da área a amônia $\left(\mathrm{NH}_{3}\right)$ foi identificada na água subterrânea em concentrações acima do limite estabelecido pela Portaria 518 do Ministério da Saúde. Em poços localizados nas Áreas $\mathrm{B}$ e C o nitrato apresentou-se também com valores acima do limite de intervenção da CETESB. A condutividade hidráulica média na área é de $4,70 \times 10^{-4} \mathrm{~cm} / \mathrm{s}$. Elaborou-se um modelo matemático interpolando dados de condutividade hidráulica e de análise químicas o que permitiu definir que o fluxo subterrâneo principal segue no sentido oeste, em direção ao Rio Perequê. Os resultados do modelo sugerem que o aporte de água com concentrações acima dos padrões adotados para amônia do aquífero para o rio tende a sofrer declínio até extinção num período de 10 anos. Em função da dimensão atual da pluma e dos níveis de concentrações observados, a modelagem indicou que a pluma com concentrações acima do limite de intervenção não será extinta ao passar 20 anos (final do período simulado).

Palavras-Chave: Águas Subterrâneas. Contaminação. Compostos Nitrogenados. Íons de Metais Pesados.

\section{INTRODUÇÃO}

A preocupação com a poluição das águas subterrâneas vem se destacando nas últimas décadas, em função do aumento das fontes potenciais e efetivas de contaminação e das crescentes demandas deste recurso como fonte de abastecimento. Cerca de $60 \%$ da população brasileira é abastecida com água subterrânea, para fins domésticos, $6 \%$ se auto-abastece das águas de poços rasos, $12 \%$ de nascentes ou fontes e $43 \%$ de poços profundos (IBGE, 2003).

$\mathrm{O}$ nitrato $\left(\mathrm{NO}_{3}^{-}\right)$com características móveis e persistentes é uma das formas contaminantes

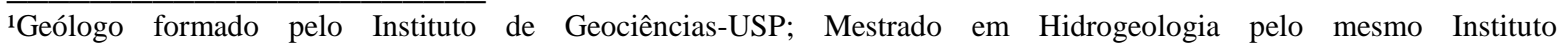
(robercal@bol.com.br).

2Professor do Departamento de Geologia Sedimentar e Ambiental do Instituto de Geociências-USP; coordenador do Laboratório de Hidrogeoquímica III - CEPAS/IGc-USP (rhypo@igc.usp.br).

${ }^{3}$ Geóloga, Mestre e Doutora pelo Instituto de Geociências-USP (sibezaki@ yahoo.com.br).
} 
mais comuns encontradas nas águas subterrâneas No meio ambiente o nitrogênio ocorre como gás $\left(\mathrm{N}_{2}\right)$, também ocorre no meio ambiente como amônio $\left(\mathrm{NH}_{4}^{+}\right)$, amônia $\left(\mathrm{NH}_{3}\right)$, nitrito $\left(\mathrm{NO}_{2}^{-}\right)$, na forma de óxidos de nitrogênio ( $\mathrm{NO}, \mathrm{N}_{2} \mathrm{O}, \mathrm{N}_{2} \mathrm{O}$ etc.) e fazendo parte de moléculas orgânicas. No meio natural, tanto terrestre como aquático, ele é continuamente reciclado por bactérias, plantas e animais sendo o amônio/amônia, nitrito e nitrato as formas inorgânicas nitrogenadas essenciais de seu ciclo.

As transformações dos compostos nitrogenados ocorrem através de mecanismos que fazem parte do ciclo do nitrogênio na atmosfera onde se incluem fixação (biológica e não biológica), amonificação, nitrificação e desnitrificação.

Grande parte das substâncias nitrogenadas nas águas pode ser convertida a nitrato e assim, fontes primárias como esgoto doméstico, fossas sépticas, excremento de animal de criação e fertilizantes (nitratos de amônia e potássio, sulfato de amônia) podem ser consideradas fontes potenciais desse ânion (KEENEY, 1989). Para seu controle e/ou remoção no tratamento de águas subterrâneas contaminadas os mecanismos utilizados baseiamse nos processos de fixação, amonificação, síntese, nitrificação e denitrificação (USEPA, 1993).

Embora fontes dispersas ou multipontuais, como as atividades agrícolas e os sistemas de saneamento in situ, tenham se destacado por ocuparem grandes áreas com manipulação ou disposição de compostos nitrogenados no solo (SUTHERSAN, 1996), as fontes pontuais de contaminação por resíduos industriais também podem gerar efeitos deletérios ao meio ambiente.

Entre as décadas 1950 e 1990 uma empresa realizou atividades no ramo de produção de materiais sintéticos em uma área de aproximadamente $42000 \mathrm{~m}^{2}$, no Município de Cubatão (SP). Sua principal linha de produção consistia na fabricação de resinas sintéticas, poliéster, metanol e formaldeído tendo a uréia como um dos principais produtos utilizados para formar o polímero. As estocagens e descartes indevidos da uréia foram responsáveis pela contaminação do solo e da água subterrânea em praticamente toda a área.

Entre 1997 e 2007, foram realizados trabalhos de investigação ambiental tendo sido identificada a presença de compostos nitrogenados no solo e águas subterrâneas, especialmente em locais de estocagem e de manipulação de uréia. Em alguns poços de monitoramento, identificaram-se elevadas concentrações de nitrogênio amoniacal, acima do limite de intervenção $(1,5 \mathrm{mg} / \mathrm{L})$ da Portaria $\mathrm{N}^{\circ}$ 518 do Ministério da Saúde (BRASIL, 2004). Visando atender às exigências dos órgãos ambientais, os resíduos, bem como parte do solo degradado, foram destinados a tratamentos adequados e parte descartada na área.

Este trabalho teve como proposta detectar e quantificar os compostos nitrogenados e os íons de metais pesados ( $\mathrm{Pb}$ e $\mathrm{Ni}$ ) associados ao solo e água subterrânea em área industrial desativada situada na Região de Cubatão e estudar mecanismos de transporte e fixação desses agentes contaminantes.

\section{ÁREA DE ESTUDO}

A área de estudo localiza-se na Rodovia Piaçaguera-Guarujá (Rodovia Cônego Domênico Rangoni), Município de Cubatão, Baixada Santista-SP, nas coordenadas $23^{\circ} 53^{\prime} 30^{\prime \prime} \mathrm{S}$ e $46^{\circ} 25^{\prime} 30^{\prime \prime}$ W (Figura 1).

O Pólo Industrial do Município de Cubatão está assentado nos contrafortes da Serra do Mar, no Complexo Costeiro do Estado de São Paulo, com predomínio de rochas pré-Cambrianas representadas por migmatitos de estruturas variadas e de sedimentos da Planície Costeira. Os sedimentos da Planície Costeira são constituídos essencialmente por depósitos continentais marinhos ou flúviolacustres, depósitos eluvio-coluvionares de natureza areno-argilosa e depósitos variados associados a encostas (IPT, 1981).

A mineralogia dos sedimentos é constituída de quartzo, caulinita, gibbsita, além de illita, flogopita, montmorillonita e feldspatos em pontos isolados. Minerais pesados como epidoto, sillimanita, anfibólios e piroxênios ocorrem secundariamente. A formação da assembléia de minerais presentes no sedimento provavelmente sofre contribuição dos gnaisses do Complexo Costeiro, muito próximos à área de estudo, que sofreram erosão e aterramento, também fornecendo sedimentos argilosos (FERRER, 2001).

Investigações realizadas na área confirmaram a existência de duas unidades hidrogeológicas representadas por um aquífero superior livre e outro inferior confinado. $\mathrm{O}$ aquífero superior corresponde a um pacote sedimentar composto por uma camada superficial de areia fina, pouco argilosa, de sedimentos de mangue, sobrepostos a sedimentos flúvio-lagunares representados por argilas com eventuais intercalações arenosas, e sedimentos marinhos. Por meio de sondagens, observou-se que a superfície livre deste aquífero se apresenta subaflorante e se estende até cerca de $30 \mathrm{~m}$ de profundidade, quando se inicia o aquífero inferior. Apresenta baixa capacidade de explotação, evidenciada por baixos valores de vazão, de condutividade hidráulica e de transmissividade, característico de materiais argilosos. Sua porosidade efetiva média foi estimada em $20 \%$, obtida experimentalmente 
para sedimentos silto-argilosos (FETTER, 2001).

No aquífero inferior, ocorre uma camada de material granular na base do pacote sedimentar, representada por areias e cascalhos de origem flúvio-lagunar, flúvio-marinha e fluvial, com espessuras médias que atingem mais de $10 \mathrm{~m}$ até o limite do Embasamento Cristalino (CONSULTORIA PAULISTA, 2004).

A área, com aproximadamente $180 \mathrm{~km}^{2}$ (Figura 1), está inserida na Bacia do Cubatão, onde se destacam o Rio Cubatão, o mais importante da região, e o Rio Capivari, considerado seu principal afluente da margem direita. À margem esquerda do Rio Cubatão também se destacam o Rio das Pedras e o Rio Perequê, ambos de interesse neste trabalho.

Devido à proximidade da Serra do Mar, os rios que banham Cubatão são curtos e torrenciais. Como quase não há declividade na planície sedimentar que separa a Serra do Mar do litoral, o processo de aluvionamento é muito grande (TORRES et al., 2002). Como consequência, tem-se a formação de meandros que resultam de erosão e acumulação das águas fluviais e de mangues.

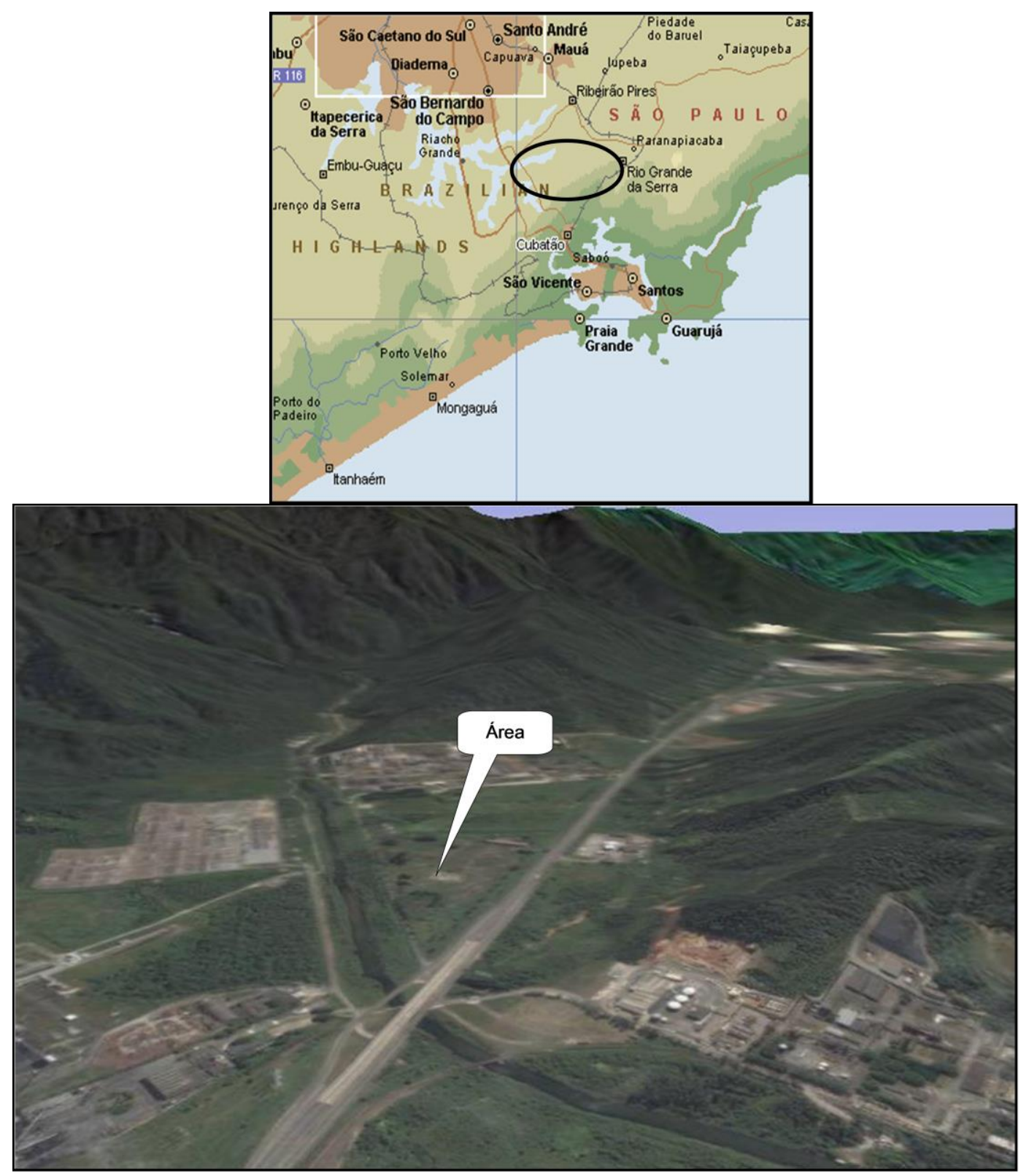

Figura 1 - Localização da área de estudos em Cubatão, SP.

Figure 1 - Study area location in Cubatão, SP.

Fonte: Google Earth.

Source: Google Earth. 


\section{MATERIAIS E MÉTODOS}

Os trabalhos foram organizados e desenvolvidos fundamentalmente em duas etapas. A primeira consistiu na instalação de poços de monitoramento com coleta de amostras de solo, amostragem de água subterrânea e realização de testes para determinação de condutividade hidráulica. A segunda constou de caracterizações das propriedades químicas e físico-químicas das amostras de solo e água, bem como a elaboração de um modelo numérico de fluxo e transporte de contaminantes.

As perfurações de 4 poços, P-01 a P-04, nas áreas A (branco de campo), B (Spray dry), C (Produção de resina) e D (Descampada), (Figura 2), foram realizadas para coleta de amostras de solo e instalação de poços de monitoramento, construídos conforme as Normas NBR 13895 e NBR 15495-1 da Associação Brasileira de Normas Técnicas - ABNT $(1997,2007)$ e CETESB (2001).

As profundidades dos poços variaram de $2,10 \mathrm{~m}$ a $4,30 \mathrm{~m}$ e é importante ressaltar que na área $\mathrm{D}$, antes dos trabalhos de campo houve, por parte de uma empresa de consultoria, remoção do solo/resíduo e aterramento com solo de outra área. Desta forma, na área $\mathrm{D}$ a coleta limitou-se apenas à amostragem de água subterrânea.

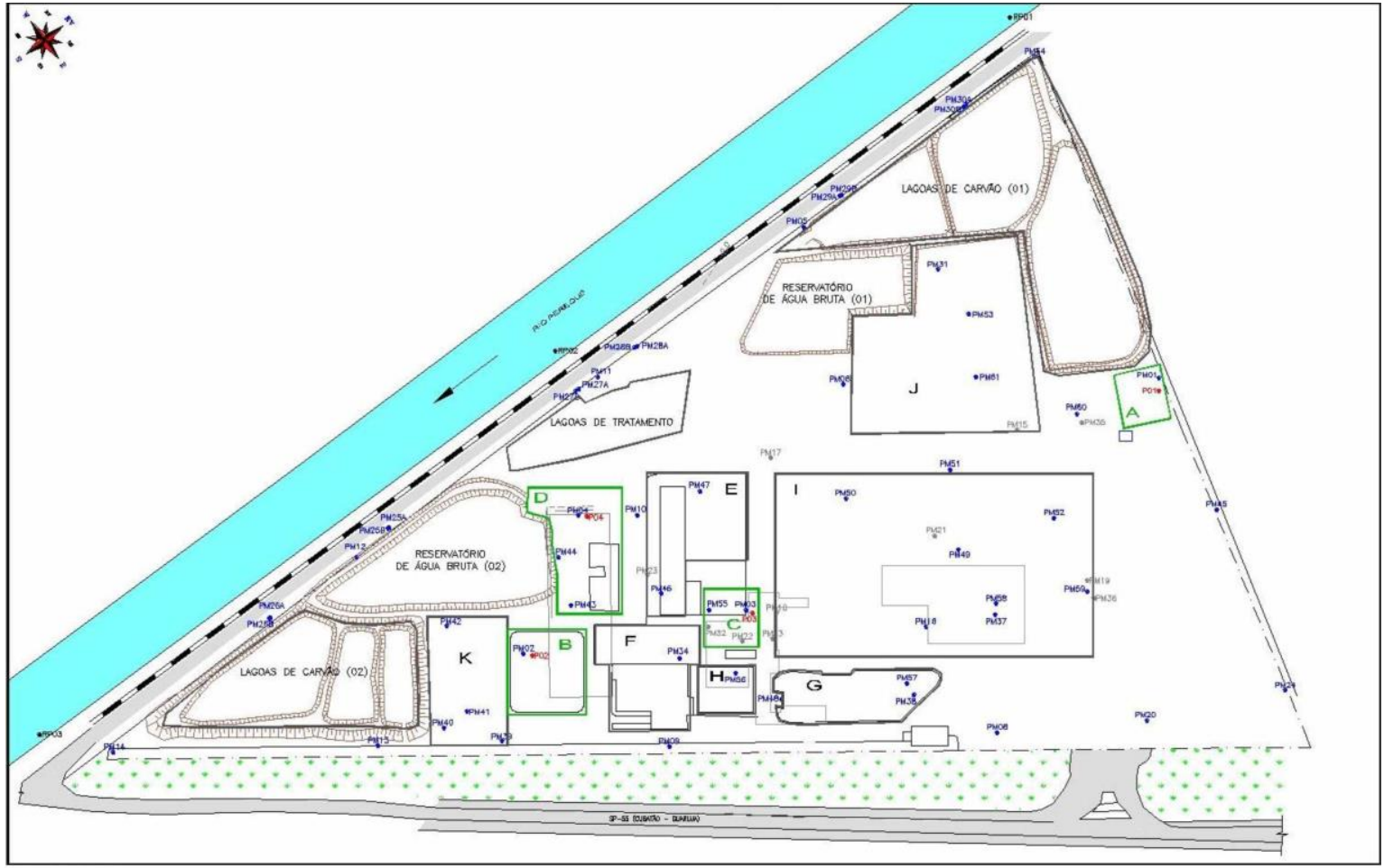

Poço de Monitoramento Existente Poço de Monitoramento Destruído

Ponto de Amostragem de Solo e Água Subterrânea

Ponto de Amostragem de Água Superficial

A Área de Amostragem de Água Subterrânea

Área de Amostragem de Solo e Água Subterrânea

\section{ÁREA DE AMOSTRAGEM DE SOLO E ÁGUA SUBTERRÂNEA}

A - Montante (branco de campo)

B - Spray-dry

C - Produção de resina

D - Área descoberta

\section{ÁREA DE AMOSTRAGEM DE ÁGUA SUBTERRÂNEA}

E - Armazenamento

F - Área de produtos acabados

G - Área de produção de Formaldeído

$\mathrm{H}$ - Tanques de estireno

I - Área de produção de metanol

$\mathrm{J}$ - Descarfa e tancagem

$\mathrm{K}$ - Área de armazenamento de tambores vazios

Figura 2 - Localização das perfurações realizadas na área de estudo.

Figure 2 - Location of perforations in the study area. 
As amostras de solo foram secas à temperatura ambiente em bandejas, destorroadas, homogeneizadas, quarteadas, peneiradas, separando-se as frações menores que $2 \mathrm{~mm}$ para as análises granulométricas, mineralógicas e químicas.

As análises granulométricas foram efetuadas no Laboratório de Geoquímica-IGc-USP aplicando o Método da Pipeta de Robson (dispersão total) e peneiramento. A análise mineralógica das frações silte e argila de solo/sedimento foi feita através de Difratometria de Raios X com radiação $\mathrm{Cu} \mathrm{K \alpha}$ (X/D5000-Siemens) no Laboratório de DRX, IGc/USP. A determinação da concentração total de íons metálicos dos solos/sedimentos foi efetuada por Fluorescência de Raios X (PW2400Phillips - Laboratório de FRX, IGc/USP).

Para determinar a natureza das cargas das partículas coloidais dos solos, foram determinados os $\Delta \mathrm{pH}\left(\mathrm{pH}_{\mathrm{H}_{2} \mathrm{O}}-p \mathrm{H}_{\mathrm{KCl}}\right)$ das amostras conforme Tan (1993) e Mekaru e Uehara (1972). As determinações de $\mathrm{pH}$ foram efetuadas conforme Camargo et al. (1986), EMBRAPA (1997) e Raij et al.(1987, 2001). A capacidade de troca catiônica (CTC) foi calculada pela soma dos cátions trocáveis $\left(\mathrm{K}^{+}, \mathrm{Ca}^{2+}, \mathrm{Mg}^{2+}\right)$ com acidez potencial $\left(\mathrm{H}^{+}+\right.$ $\mathrm{Al}^{3+}$ ) no Laboratório de Fertilidades dos Solos da ESALQ-USP.

Foram realizadas extrações utilizando água para quantificar íons intersticiais no solo, e extrações dos íons adsorvidos à fase sólida e intersticiais em meio nítrico $\left(\mathrm{HNO}_{3} 8 \mathrm{M}\right)$, conforme metodologia de Marques (2003) e Hypolito et al. (2009). Para determinação dos teores dos íons metálicos as soluções foram analisadas por ICP-OES no Laboratório de Química do IGc/USP.

As amostras de água dos poços foram coletadas utilizando amostrador descartável (bailer) e medições de parâmetros como temperatura, $\mathrm{pH}$, condutividade elétrica (CE), Eh, oxigênio dissolvido (OD) utilizando medidores portáteis. As alcalinidades (parcial e total) foram determinadas segundo o método desenvolvido por Hypolito et al. (2008). As amostras foram acondicionadas em frascos plásticos de PEAD, preservadas com $\mathrm{HNO}_{3}$ ou $\mathrm{H}_{2} \mathrm{SO}_{4}$, e refrigeradas em temperatura entre $2^{\circ} \mathrm{C}$ e $6^{\circ} \mathrm{C}$. Em seguida, as amostras foram encaminhadas ao Laboratório de Hidrogeoquímica III (CEPAS-IGc/USP), e analisadas por Espectrofotometria de Absorção Atômica de Chama (CGAA7000BC) para cátions e por cromatografia líquida (Dionex2020i) para ânions. As amostras foram acondicionadas em frascos plásticos de PE$\mathrm{AD}$, preservadas com $\mathrm{HNO}_{3}$ ou $\mathrm{H}_{2} \mathrm{SO}_{4}$, e refrigeradas em temperatura entre $2^{\circ} \mathrm{C}$ e $6^{\circ} \mathrm{C}$. Em seguida, as amostras foram encaminhadas ao Laboratório de
Hidrogeoquímica III (CEPAS-IGc/USP), e analisadas por Espectrofotometria de Absorção Atômica de Chama (CGAA7000BC) para cátions e por cromatografia líquida (Dionex2020i) para ânions.

Também foram amostradas águas do Rio Perequê em três pontos: na porção montante, no centro e a jusante em relação à área de estudo. Para avaliar a qualidade de sua água, foram também efetuadas leituras de seus parâmetros químicos e físico-químicos.

Foram utilizados dados existentes de 46 poços de monitoramento fornecidos pela empresa que atuou na área de estudo, ou seja, levantamento planialtimétrico, dados construtivos dos poços e resultados de análises químicas (série nitrogenada) e físico-químicas das águas.

Testes de condutividade hidráulica (slug test) foram realizados em 5 poços de monitoramento: PM-02 (Área A), PM-03 (Área C), PM-31 (Área J), PM-50 (Área I) e PM-59 (Área I) sendo os cálculos realizados pelo software Aquifer Test, baseado no Método de Hvorslev (1951 apud OLIVEIRA, 1992).

A modelagem matemática numérica objetivou avaliar o escoamento do fluxo subterrâneo e transporte na Zona Saturada. Foi utilizado o modelo "USGS Modular 3D Finite Difference Groundwater Flow Model" conhecido como Visual MODFLOW (MCDONALD e HARBAUGH, 1988), e o "Modular 3D Finite Difference Mass Transport Model" - MT3DMS. O método numérico para resolver o sistema de equações lineares gerado pela discretização espacial da equação de água subterrânea na área foi o WHS (Waterloo Hydrogeologic Solver). Os parâmetros empregados foram os fornecidos pelo fabricante.

\section{RESULTADOS E DISCUSSÃO Análise granulométrica}

Os resultados das análises granulométricas (Tabela 1) foram projetados em diagrama triangular de Shepard (1954) e indicam predomínio da fração areia - areia síltica, exceção feita à amostra P-03c (Área C) que se enquadra no limite entre silte argiloso e silte arenoso.

\section{Análise mineralógica}

A mineralogia das frações argila/silte é uniforme, constituída essencialmente por caulinita $\left(\mathrm{Al}_{2} \mathrm{Si}_{2} \mathrm{O}_{5}(\mathrm{OH})_{4}\right)$, gibbsita $\left(\mathrm{Al}(\mathrm{OH})_{3}\right)$ e illita $\left(\mathrm{KAl}_{2}\left(\mathrm{Si}_{3} \mathrm{Al}\right) \mathrm{O}_{10}(\mathrm{OH})_{2}\right)$. A intensa precipitação e distribuição pluviométrica irregular favorecem a formação destes minerais que são oriundos de intemperismo das rochas granito-gnáissicas da Serra do Mar, caracterizando sua origem alóctone (FERRER, 2001). 
Tabela 1 - Análise granulométrica dos materiais amostrados.

Table 1 - Granulometric analysis of sampled materials.

\begin{tabular}{cccccc}
\hline Área & Amostra & Profundidade $(\boldsymbol{m})$ & Argila (\%) & Silte (\%) & Areia (\%) \\
\hline \multirow{6}{*}{ A-01a } & 0,00 a 0,70 & 10,81 & 24,06 & 64,16 \\
& P-01b & 0,70 a 1,30 & 14,38 & 31,34 & 52,78 \\
& P-01c & 1,30 a 2,10 & 16,11 & 32,17 & 49,95 \\
& P-01d & 2,10 a 2,80 & 7,34 & 19,66 & 71,70 \\
& P-01e & 2,80 a 3,40 & 7,54 & 17,22 & 75,17 \\
& P-02a & 0,00 a 0,30 & 14,17 & 37,33 & 49,14 \\
B & P-02b & 0,40 a 1,20 & 10,50 & 36,93 & 52,47 \\
& P-02c & 1,20 a 2,10 & 10,40 & 27,19 & 62,13 \\
& P-03a & 0,00 a 0,40 & 8,77 & 42,45 & 48,59 \\
C & P-03b & 0,40 a 1,20 & 7,24 & 44,23 & 49,95 \\
& P-03c & 1,40 a 2,00 & 22,33 & 56,10 & 22,56 \\
& P-03d & 2,00 a 3,20 & 5,40 & 34,43 & 59,90 \\
\hline
\end{tabular}

\section{pH e $\Delta$ pH}

Os valores de $\Delta \mathrm{pH}$ (Tabela 2) positivos indicam presença predominante de cargas negativas

nas partículas coloidais, portanto, aptas a adsorverem cátions das soluções intersticiais.

Tabela 2 - Resultados das determinações de $\mathrm{pH}$ e $\Delta \mathrm{pH}$ do solo.

Table 2 - Results of soil $\mathrm{pH}$ and $\Delta \mathrm{pH}$ determinations.

\begin{tabular}{|c|c|c|c|c|}
\hline \multirow{2}{*}{ Área } & \multirow{2}{*}{ Amostra } & \multicolumn{2}{|c|}{$\mathrm{pH}$} & \multirow{2}{*}{$\Delta \mathrm{pH}$} \\
\hline & & $\mathrm{H}_{2} \mathrm{O}$ & $\mathrm{KCl}$ & \\
\hline \multirow{6}{*}{ A } & P-01a & 6,6 & 4,3 & $+2,3$ \\
\hline & P-01b & 5,1 & 4,1 & $+1,0$ \\
\hline & P-01c & 5,1 & 4,2 & $+0,9$ \\
\hline & P-01d & 5,6 & 4,5 & $+1,1$ \\
\hline & P-01e & 4,9 & 4,2 & $+0,7$ \\
\hline & P-02a & 8,1 & 7,8 & $+0,3$ \\
\hline \multirow{2}{*}{ B } & $P-02 b$ & 7,3 & 6,8 & $+0,5$ \\
\hline & $P-02 c$ & 8,3 & 7,8 & $+0,5$ \\
\hline \multirow{4}{*}{$C$} & P-03a & 6,8 & 6,3 & $+0,5$ \\
\hline & P-03b & 7,5 & 6,5 & $+1,0$ \\
\hline & P-03c & 8,2 & 6,8 & $+1,4$ \\
\hline & P-03d & 7,9 & 6,8 & $+1,1$ \\
\hline
\end{tabular}

\section{CTC}

Os valores de CTC encontrados na área (Tabela 3) são considerados baixos, característicos de regiões tropicais, onde os solos são intemperizados, predominando argilas de baixa atividade de adsorção e teor baixo a médio de matéria orgânica (LOPES e GUILHERME, 2004).

Esses baixos valores confirmam a composição mineral dos materiais, isto é, predomínio de caulinita (argilomineral 1:1) e baixos teores de matéria orgânica. É de se levar em conta também a presença de óxidos/hidróxidos de alumínio e ferro, que se constituem na fração argila com cargas positivas (MONIZ, 1972; Hypolito et al., 2011) que poderiam, eventualmente, fixar ânions como $\mathrm{NO}_{3}^{-}, \mathrm{Cl}^{-}, \mathrm{HCO}_{3}^{-} / \mathrm{CO}_{3}^{2-}, \mathrm{PO}_{4}^{3-}$ e $\mathrm{SO}_{4}^{2-}$ que, no entanto, são solúveis e bastante móveis. Solos expostos a processos intempéricos prolongados e intensos apresentam argilas com expressivo conteúdo de óxidos e óxidos hidratados de ferro e alumínio. Nas Regiões Tropicais e Subtropicais, a formação desses produtos secundários, cristalinos ou não, é favorecida pelas condições de intensa lixiviação com remoção de sílica (dessilicatização completa) e das bases do solo $(\mathrm{Ca}, \mathrm{Mg}, \mathrm{K})$.

A porcentagem de Saturação por Bases da CTC a pH 7 (V) reflete os sítios de troca de cátions dos materiais coloidais ocupados por bases. Corresponde à porcentagem de cargas negativas, passiveis de troca a $\mathrm{pH} 7,0$, ocupadas por íons $\mathrm{Ca}, \mathrm{Mg}$, $\mathrm{K}$ e , às vezes, Na (LOPES E GUILHERME, 2004). Os valores de V (\%) das amostras das Áreas B e C são bem superiores aos da Área A, indicando que aproximadamente 99\% (Área B) e 85\% (Área C) dos pontos de troca de cátions potencial do complexo coloidal do solo estão ocupados por bases nas amostras de solo destas áreas. Isto comprova que a área $\mathrm{A}$, com valores baixos de $\mathbf{V}$ (média de $26 \%$ ), pode ser tomada como referência (branco). 
Tabela 3 - Dados dos teores de Matéria Orgânica (M.O.) e capacidade de troca catiônica (CTC) do solo, Table 3 - Data of soil organic matter and CEC contents.

\begin{tabular}{cccccc}
\multirow{2}{*}{ Área } & Amostra & M.O. & CTC a pH 7,0 & V & M \\
\cline { 2 - 6 } & & g kg-1 $^{-1}$ & mmolc kg-1 $^{-1}$ & \multicolumn{3}{c}{$\%$} \\
\hline \multirow{4}{*}{ A } & P-01a & 11 & 26,8 & 22 & 41 \\
& P-01b & 23 & 55 & 20 & 42 \\
& P-01c & 26 & 64,5 & 24 & 24 \\
& P-01d & 12 & 33 & 33 & 8 \\
& P-01e & 9 & 25,3 & 33 & 27 \\
B & P-02a & 9 & 118,8 & 99 & 0 \\
& P-02b & 10 & 45,1 & 98 & 0 \\
& P-02c & 9 & 97,6 & 99 & 0 \\
C & P-03a & 10 & 54 & 96 & 0 \\
& P-03b & 8 & 24,4 & 71 & 0 \\
& P-03c & 10 & 61,5 & 87 & 0 \\
\hline
\end{tabular}

$\mathrm{V}(\%)$ : porcentagem de saturação por bases da CTC a pH 7,0;

$\mathrm{m}(\%)$ : porcentagem de saturação por alumínio $(\mathrm{m})$.

O parâmetro $\mathbf{m}$ representa a porcentagem de saturação por alumínio que, por sua vez, reflete o teor de cargas negativas do solo, próximos ao $\mathrm{pH}$ natural, ocupada por $\mathrm{Al}$ trocável. Em geral, quanto mais ácido é um solo, maior o teor de $\mathrm{Al}$ trocável em valor absoluto. As amostras da Área A apresentam valores elevados de m (\%) comparados aos valores de $\mathrm{B}$ e $\mathrm{C}(\mathrm{m} \%=0)$. Os resultados da porcentagem de saturação por Al na Área A podem estar relacionados com $\mathrm{pH}$ do solo que apresenta características ácidas, sendo coerente com os resultados de $\mathbf{V}$.

\section{Análises químicas do solo}

A composição química do solo é constituída essencialmente de sílica e óxidos de alumínio e ferro (Tabela 4a). Não foi identificada concentração de metais acima dos valores de referência CETESB (2005) para solo em área industrial (Tabela 4b). Entretanto, deve ser salientado que as concentrações de $\mathrm{Pb}$ nas Áreas $\mathrm{B}$ e $\mathrm{C}$ são significativamente maiores (entre 57 e $281 \mathrm{mg} \mathrm{kg}^{-1}$ ) em relação a Área $\mathrm{A}\left(<29 \mathrm{mg} \mathrm{kg}^{-1}\right)$, chegando a ultrapassar valores de prevenção da CETESB.

Tabela 4 - Composição química de solos das áreas A, B e C: (a) elementos maiores (\%) e (b) traços $\left(\mathrm{mg} \mathrm{kg}^{-1}\right)$. Table 4 - Chemical composition of soils from áreas A, B and C: (a) major elements (\%) and (b) trace $\left(\mathrm{mg} \mathrm{kg}^{-1}\right)$.

(a)

\begin{tabular}{|c|c|c|c|c|c|c|c|c|c|c|c|c|c|}
\hline \multirow{2}{*}{$\begin{array}{c}\text { Elementos } \\
\text { Maiores }\end{array}$} & \multirow{2}{*}{ VR } & \multicolumn{5}{|c|}{ Área A } & \multicolumn{3}{|c|}{ Área B } & \multicolumn{4}{|c|}{ Área C } \\
\hline & & P-01a & $P-02 b$ & P-01c & P-01d & P-01e & $\mathrm{P}-02 \mathrm{a}$ & $P-02 b$ & P-02C & P-03a & $P-03 b$ & $P-03 c$ & $P-03 d$ \\
\hline $\mathrm{SiO}_{2}$ & $\mathrm{SiO}_{2}$ & 69,45 & 69,33 & 68,98 & 72,91 & 73,98 & 63,45 & 64,61 & 68,31 & 63,56 & 65,51 & 56,86 & 70,34 \\
\hline $\mathrm{Al}_{2} \mathrm{O}_{3}$ & $\mathrm{Al}_{2} \mathrm{O}_{3}$ & 14,50 & 13,37 & 13,47 & 12,04 & 10,66 & 19,52 & 18,49 & 16,30 & 19,76 & 19,41 & 20,84 & 14,00 \\
\hline $\mathrm{MnO}$ & $\mathrm{MnO}$ & 0,08 & 0,09 & 0,09 & 0,08 & 0,05 & 0,06 & 0,06 & 0,06 & 0,05 & 0,08 & 0,07 & 0,05 \\
\hline $\mathrm{MgO}$ & $\mathrm{MgO}$ & 1,12 & 1,49 & 1,46 & 1,32 & 1,19 & 0,65 & 0,69 & 0,71 & 1,01 & 1,00 & 1,59 & 1,90 \\
\hline $\mathrm{CaO}$ & $\mathrm{CaO}$ & 0,13 & 0,33 & 0,32 & 0,23 & 0,17 & 0,25 & 0,59 & 0,49 & 0,19 & 0,08 & 0,30 & 0,35 \\
\hline $\mathrm{Na}_{2} \mathrm{O}$ & $\mathrm{Na}_{2} \mathrm{O}$ & 0,41 & 0,31 & 0,29 & 0,23 & 0,27 & 0,41 & 0,26 & 0,24 & 0,46 & 0,18 & 0,37 & 0,26 \\
\hline $\mathrm{K}_{2} \mathrm{O}$ & $\mathrm{K}_{2} \mathrm{O}$ & 2,18 & 1,84 & 1,82 & 2,21 & 1,95 & 1,53 & 1,57 & 1,78 & 1,92 & 1,23 & 2,51 & 2,05 \\
\hline $\mathrm{TiO}_{2}$ & $\mathrm{TiO}_{2}$ & 0,81 & 0,78 & 0,79 & 0,68 & 0,61 & 0,84 & 0,82 & 0,73 & 0,78 & 0,71 & 1,17 & 0,73 \\
\hline $\mathrm{P}_{2} \mathrm{O}_{5}$ & $\mathrm{P}_{2} \mathrm{O}_{5}$ & 0,07 & 0,09 & 0,09 & 0,06 & 0,04 & 0,12 & 0,12 & 0,09 & 0,13 & 0,08 & 0,07 & 0,06 \\
\hline $\mathrm{Fe}_{2} \mathrm{O}_{3}$ & $\mathrm{Fe}_{2} \mathrm{O}_{3}$ & 5,78 & 5,62 & 5,66 & 5,69 & 6,94 & 5,79 & 5,22 & 4,83 & 4,95 & 4,64 & 8,05 & 5,33 \\
\hline $\mathrm{H}_{2} \mathrm{O}^{+}$ & $\mathrm{H}_{2} \mathrm{O}^{+}$ & 5,91 & 7,02 & 7,46 & 4,65 & 4,11 & 7,86 & 7,62 & 6,29 & 7,81 & 7,88 & 8,74 & 5,08 \\
\hline Total & Total & 100,44 & 100,27 & 100,43 & 100,10 & 99,97 & 100,48 & 100,05 & 99,84 & 100,61 & 100,81 & 100,56 & 100,15 \\
\hline
\end{tabular}

$\mathrm{H}_{2} \mathrm{O}^{+}$- Perda ao fogo. 
Tabela 4 - Composição química de solos das áreas A, B e C: (a) elementos maiores (\%) e (b) traços $\left(\mathrm{mg} \mathrm{kg}^{-1}\right)$.

Table 4 - Chemical composition of soils from áreas A, B and C: (a) major elements (\%) and (b) trace $\left(\mathrm{mg} \mathrm{kg}^{-1}\right)$. (b)

\begin{tabular}{|c|c|c|c|c|c|c|c|c|c|c|c|c|c|c|}
\hline \multirow{2}{*}{$\begin{array}{c}\text { Elementos } \\
\text { Traço }\end{array}$} & \multirow{2}{*}{$V^{*}$} & \multirow{2}{*}{$\mathrm{VP}^{* *}$} & \multicolumn{5}{|c|}{ Área A } & \multicolumn{3}{|c|}{ Área B } & \multicolumn{4}{|c|}{ Área C } \\
\hline & & & P-01a & $P-02 b$ & P-01c & P-01d & P-01e & P-02a & $P-02 b$ & P-02C & P-03a & P-03b & $P-03 c$ & $P-03 d$ \\
\hline $\mathrm{Cr}$ & 40 & 75 & 62 & 62 & 67 & 68 & 57 & 49 & 24 & 60 & 40 & 12 & 53 & $<13$ \\
\hline $\mathrm{Cu}$ & 35 & 60 & 30 & 26 & 26 & 26 & 19 & 21 & 14 & 10 & 22 & 10 & 10 & 9 \\
\hline $\mathrm{Ni}$ & 13 & 30 & 34 & 27 & 30 & 25 & 24 & 27 & 16 & 14 & 25 & 12 & 14 & 12 \\
\hline $\mathrm{Pb}$ & 17 & 72 & 29 & 24 & 28 & 12 & 6 & 57 & 270 & 228 & 63 & 252 & 280 & 281 \\
\hline $\mathrm{Zn}$ & 60 & 300 & 94 & 84 & 87 & 73 & 70 & 77 & 64 & 63 & 90 & 52 & 76 & 62 \\
\hline
\end{tabular}

*VR: Valores de Referência de Qualidade; **VP: Valores de Prevenção (CETESB, 2005).

\section{Extrações aquosa e nítrica}

Para determinação de íons intersticiais, mentos com água e com $\mathrm{HNO}_{3}(8 \mathrm{M})$ : Tabelas 5 a, bem como os adsorvidos à fase solida associados b e c.

ao solo, foram efetuados, respectivamente, trata-

Tabela 5 - Extração seletiva de ânions (a) e cátions (b) do solo em água, e extração seletiva de cátions do solo com $\mathrm{HNO}_{3}$ (c).

Table 5 - Selective extraction of soil anions (a) and cations (b) in water, and selective extraction of soil cations with $\mathrm{HNO}_{3}$ (c).

(a)

\begin{tabular}{cccc}
\hline \multirow{2}{*}{ Localização } & Ânions $\left(\mathrm{mg} \mathrm{kg}^{-1}\right)$ & $\mathrm{NO}_{2}{ }^{-}$ & $\mathrm{NO}_{3}{ }^{-}$ \\
\cline { 2 - 4 } & Limites de detecção & 0,40 & 1,90 \\
\hline \multirow{4}{*}{ Área A } & P-01a & $<\mathrm{LD}$ & 47,00 \\
& P-01b & $<\mathrm{LD}$ & 40,00 \\
& P-01c & $<\mathrm{LD}$ & 42,60 \\
& P-01d & $<\mathrm{LD}$ & 38,40 \\
Área B & P-01e & 2,50 & 36,50 \\
& P-02a & 5,10 & 93,00 \\
& P-02b & 6,40 & 29,00 \\
Área C & P-02c & 3,60 & 42,30 \\
& P-03a & 6,60 & 129,00 \\
& P-03b & 1,60 & 102,00 \\
& P-03c & 1,40 & 161,00 \\
\hline & P-03d &
\end{tabular}

(b)

\begin{tabular}{cccccccccc}
\hline \multirow{2}{*}{ Localização } & Cátions $\left(\mathrm{mg} \mathrm{kg}^{-1}\right)$ & $\mathrm{Al}$ & $\mathrm{Cr}$ & $\mathrm{Fe}$ & $\mathrm{Ni}$ & $\mathrm{Cu}$ & $\mathrm{Cd}$ & $\mathrm{Pb}$ & $\mathrm{Zn}$ \\
\cline { 2 - 9 } & Limite de detecção & 0,2 & 0,05 & 1 & 0,03 & 0,02 & 0,001 & 0,001 & 0,05 \\
\hline \multirow{4}{*}{ Área A } & CETESB * industrial & - & $\mathbf{4 0 0}$ & - & $\mathbf{1 3 0}$ & $\mathbf{6 0 0}$ & $\mathbf{2 0}$ & $\mathbf{9 0 0}$ & $\mathbf{2 0 0 0}$ \\
& $\mathbf{P - 0 1 a}$ & 41,00 & $<0,05$ & 58,00 & 0,39 & 0,34 & 0,006 & 0,13 & 0,76 \\
& $\mathbf{P - 0 1 b}$ & 42,40 & 0,10 & 75,00 & 0,20 & 0,37 & 0,005 & 0,15 & 0,62 \\
& P-01c & 57,50 & 0,19 & 84,00 & 0,36 & 5,76 & 0,006 & 0,22 & 0,96 \\
& P-01d & 49,70 & 0,12 & 76,00 & 0,14 & 0,58 & 0,003 & 0,23 & 1,17 \\
\multirow{3}{*}{ Área B } & P-01e & 37,60 & 0,09 & 56,00 & 0,14 & 0,19 & 0,006 & 0,16 & 0,56 \\
& P-02a & 27,70 & 0,09 & 17,00 & 0,82 & 0,34 & 0,01 & 0,20 & 1,11 \\
& P-02b & 71,50 & 0,69 & 28,00 & 0,26 & 0,40 & 0,004 & 1,64 & 0,51 \\
& P-02c & 93,20 & 0,59 & 49,00 & 0,24 & 0,52 & 0,005 & 0,57 & 0,98 \\
Área C & P-03a & 36,00 & 0,81 & 17,00 & 0,36 & 1,30 & 0,003 & 0,23 & 0,50 \\
& P-03b & 29,30 & 0,18 & 13,00 & 0,49 & 0,32 & 0,002 & 0,50 & 0,65 \\
& P-03c & 59,30 & 0,29 & 60,00 & 0,29 & 1,35 & 0,007 & 0,21 & 0,82 \\
& P-03d & 131,00 & 0,49 & 100,00 & 0,27 & 0,59 & 0,007 & 0,18 & 0,77 \\
\hline
\end{tabular}


Tabela 5 - Extração seletiva de ânions (a) e cátions (b) do solo em água, e extração seletiva de cátions do solo com $\mathrm{HNO}_{3}$ (c).

Table 5 - Selective extraction of soil anions (a) and cations (b) in water, and selective extraction of soil cations with $\mathrm{HNO}_{3}$ (c).

(c)

\begin{tabular}{|c|c|c|c|c|c|c|c|c|c|}
\hline \multirow{2}{*}{ Localização } & Cátions (mg kg-1) & $\mathrm{Al}$ & $\mathrm{Cr}$ & $\mathrm{Fe}$ & $\mathrm{Ni}$ & $\mathrm{Cu}$ & $\mathrm{Cd}$ & $\mathrm{Pb}$ & $\mathrm{Zn}$ \\
\hline & Limite de detecção & 0,2 & 0,05 & 1 & 0,03 & 0,02 & 0,001 & 0,001 & 0,05 \\
\hline \multirow{5}{*}{ Área A } & CETESB *industrial & - & 400 & - & 130 & 600 & 20 & 900 & 2000 \\
\hline & P-01a & $>2000$ & 4,80 & 3180 & 3,80 & 12,00 & 0,08 & 16,10 & 26,00 \\
\hline & P-01b & $>2000$ & 10,20 & $>10000$ & 3,50 & 20,70 & 0,09 & 19,00 & 22,70 \\
\hline & P-01c & $>2000$ & 11,80 & 9680 & 15,20 & 20,00 & 0,09 & 19,00 & 26,40 \\
\hline & P-01d & $>2000$ & 5,60 & 5750 & 3,00 & 10,20 & 0,05 & 10,40 & 15,80 \\
\hline \multirow{4}{*}{ Área B } & P-01e & $>2000$ & 5,20 & 3520 & 3,40 & 15,90 & 0,06 & 15,30 & 12,40 \\
\hline & $P-02 a$ & $>2000$ & 4,80 & 3100 & 4,40 & 9,90 & 0,06 & 32,10 & 30,40 \\
\hline & $P-02 b$ & $>2000$ & 7,50 & 3350 & 5,20 & 11,30 & 0,07 & 34,00 & 57,30 \\
\hline & $P-02 c$ & $>2000$ & 5,90 & 3320 & 4,50 & 14,00 & 0,07 & 29,30 & 36,00 \\
\hline \multirow{4}{*}{ Área C } & P-03a & $>2000$ & 2,60 & 2340 & 3,10 & 10,20 & 0,05 & 26,20 & 14,00 \\
\hline & P-03b & $>2000$ & 2,00 & 1320 & 4,80 & 4,80 & 0,04 & 48,60 & 11,50 \\
\hline & P-03c & $>2000$ & 11,00 & 7360 & 9,80 & 20,30 & 0,04 & 20,30 & 23,50 \\
\hline & P-03d & $>2000$ & 4,40 & 1970 & 4,50 & 10,50 & 0,06 & 12,60 & 9,60 \\
\hline
\end{tabular}

As extrações com água permitem que se separem e se identifiquem os íons que se encontram nas soluções aquosas intergranulares, que são prontamente disponíveis ao meio ambiente e o tratamento nítrico, por sua vez, consiste numa extração total que possibilita a determinação dos íons das soluções intergranulares do solo, assim como os adsorvidos. Neste caso os íons encontram-se, em parte, menos sujeitos à serem liberados ao meio ambiente.
Também não foram identificadas concentrações acima dos valores de referência CETESB, cabendo salientar, no entanto, que para os ânions estudados não existem padrões nacionais ou internacionais de comparação.

\section{Águas subterrâneas}

Os parâmetros químicos e físico-químicos das águas coletadas nos poços das 4 áreas são apresentados na Tabela 6 .

Tabela 6 - Parâmetros químicos e físico-químicos das águas subterrâneas medidos em campo.

Table 6 - Chemical and physico-chemical parameter measured in field.

\begin{tabular}{ccccccc}
\hline Área & Identificação & $\mathbf{p H}$ & $\begin{array}{c}\mathrm{Eh} \\
(\mathrm{V})\end{array}$ & $\begin{array}{c}\mathrm{CE} \\
\left(\mu \mathrm{S} \mathrm{cm}^{-1}\right)\end{array}$ & $\begin{array}{c}\text { OD } \\
\left(\mathrm{mg} \mathrm{dm}^{-3}\right)\end{array}$ & $\begin{array}{c}\text { Alcalinidade } \\
\left(\mathrm{mg} \mathrm{dm}^{-3} \mathrm{CaCO}_{3}\right)\end{array}$ \\
\hline A & P-01 & 5,96 & $+0,14$ & 159 & 2,85 & 4,11 \\
B & P-02 & 7,82 & $+0,08$ & 647 & 1,53 & 106,94 \\
C & P-03 & 6,90 & $+0,16$ & 662 & 1,36 & 34,14 \\
D & P-04 & 6,31 & $-0,04$ & 630 & 1,42 & 0,82 \\
\hline
\end{tabular}

A temperatura média da água subterrânea foi de $26,40^{\circ} \mathrm{C}$ e média de $\mathrm{pH} 6,70$. Os dados do potencial de oxirredução (Eh) indicam ambiente subterrâneo com tendências oxidantes, exceto na área D.

O total de sólidos dissolvidos (TSD) e a força iônica (I) calculados a partir dos resultados da condutividade elétrica das águas subterrâneas das Áreas B, C e D, apresentaram resultados semelhantes: valores médios de $485 \mathrm{mg} \mathrm{dm}^{-3}$ para TSD e de $1,0 \times 10^{-2}$ para I.

A alcalinidade refere-se à estabilidade das formas carbonáticas em solução que se mostraram compatíveis com os $\mathrm{pH}$ das águas correspondentes, isto é predomínio das fases $\mathrm{H}_{2} \mathrm{CO}_{3}^{*} / \mathrm{HCO}_{3}^{-}$. Os dados analíticos referentes às amostras de água subterrânea encontram-se nas Tabelas 7 e 8. 
Tabela 7 - Resultados analíticos dos ânions da água subterrânea em $\mathrm{mg} \mathrm{dm}{ }^{-3}$.

Table 7 - Analytical results of groundwater anions in $\mathrm{mg} \mathrm{dm}^{-3}$.

\begin{tabular}{cccc}
\hline Área & Identificação & $\mathbf{N}-\mathrm{NO}_{2}{ }^{-}$ & $\mathbf{N}-\mathrm{NO}_{3}{ }^{-}$ \\
\hline $\mathbf{A}$ & $\mathbf{P}-\mathbf{0 1}$ & 0,03 & 0,06 \\
$\mathbf{B}$ & $\mathbf{P - 0 2}$ & 0,34 & 8,93 \\
$\mathbf{C}$ & $\mathbf{P}-\mathbf{0 3}$ & 0,08 & 1,75 \\
$\mathbf{D}$ & $\mathbf{P - 0 4}$ & $<\mathrm{LD}$ & $<\mathrm{LD}$ \\
CETESB / Portaria 518 & $\mathbf{1}$ & $\mathbf{1 0}$ \\
\hline
\end{tabular}

LD - Limite de detecção do equipamento.

Tabela 8 - Resultados analíticos dos cátions da água subterrânea em $\mathrm{mg} \mathrm{dm}^{-3}$ (em azul valores acima do limite CETESB).

Table 8 - Analytical results of groundwater cations in $\mathrm{mg} \mathrm{dm}^{-3}$ (vales higher than CETESB limits are in blue).

\begin{tabular}{cccccc}
\hline Área & Identificação & $\mathbf{A l}^{\mathbf{3 +}}$ & $\mathbf{F e}_{\text {total }}$ & $\mathbf{N i}^{\mathbf{2 +}}$ & $\mathbf{P b}^{\mathbf{2 +}}$ \\
\hline $\mathrm{A}$ & $\mathrm{P}-01$ & $\mathbf{0 , 2 6}$ & $\mathbf{0 , 4 2}$ & $\mathrm{ND}$ & $\mathrm{ND}$ \\
$\mathrm{B}$ & $\mathrm{P}-02$ & $\mathbf{0 , 4 2}$ & 0,04 & $\mathbf{0 , 0 9}$ & $\mathbf{0 , 5 8}$ \\
$\mathrm{C}$ & $\mathrm{P}-03$ & $\mathbf{0 , 2 4}$ & 0,25 & $\mathbf{0 , 2 0}$ & $\mathbf{1 , 3 9}$ \\
$\mathrm{D}$ & $\mathrm{P}-04$ & $\mathbf{0 , 3 3}$ & $\mathbf{0 , 3 3}$ & 0,10 & $\mathbf{0 , 5 4}$ \\
& CETESB & 0,20 & 0,30 & 0,02 & 0,01 \\
\hline
\end{tabular}

ND - Não detectado.

Nos quatro poços analisados a concentração de $\mathrm{Al}^{3+}$ apresentou-se acima dos valores orientadores recomendados pela CETESB, e o $\mathrm{Fe}_{\text {total }}$ nos poços $\mathrm{P}-01$ e $\mathrm{P}-04$. A presença dos íons $\mathrm{Al}$ e $\mathrm{Fe}$ na água subterrânea, apesar dos valores de $\mathrm{pH}$ incompatíveis, pode estar associada a hidróxidos na forma aquosa $\left(\mathrm{Al}(\mathrm{OH})_{3}(\mathrm{aq})\right.$ e $\mathrm{Fe}(\mathrm{OH})_{3}(\mathrm{aq})$ ou devido a suas estabilidades em meio com elevado conteúdo iônico $\left(\mathrm{I}=1,0 \times 10^{-2}\right)$ e/ou na forma de complexos orgânicos levando em conta a natureza das atividades industriais das áreas com elevados teores de substâncias orgânicas. Vale destacar que pela composição química das amostras de solo (Tabela 4a) foram constatados elevados teores de alumínio e ferro, não se descartando a hipótese dos teores em águas estarem relacionados à composição natural das amostras, como se pode verificar na área $\mathrm{A}$, local livre de disposição de resíduos.

Os íons $\mathrm{Pb}$ e Ni ocorrem em concentrações acima dos valores de referência recomendados pela CETESB nos poços P-02, P-03 e P-04. Pelos diagramas de Eh-pH (GARRELS E CHRIST, 1965; BROOKINS, 1988; STUM E MORGAN, 1994; TAKENO, 2005) estes metais ocorrem na forma iônica livre como $\mathrm{Pb}^{2+}$ aq e $\mathrm{Ni}^{2+}$ aq. Também podem ocorrer na forma hidratada como $\mathrm{PbOH}[+]$ e $\mathrm{NiOH}[+]$, em condições de $\mathrm{pH}$ acima de 6,0 a 7,0 para o chumbo e acima de 7,7 para o níquel.

A análise química da água do poço P-01 localizado na Área A, tomada como referência, não continha esses cátions na água subterrânea. Isto pode indicar que os valores anômalos encontrados nos poços das Áreas B, C e D estão diretamente relacionados à maneira como foram estocadas e manipuladas as matérias primas, bem como a prática de enterrar resíduos no próprio terreno, atividade que era comumente realizada pelas indústrias nas décadas passadas.

\section{Condutividade elétrica, $\mathrm{pH}$ e série nitrogenada das águas superficiais e subterrâneas}

A condutividade elétrica nas águas do Rio Perequê (Figura 2), apresentou o valor médio de $23,0 \mu \mathrm{S} \mathrm{cm}^{-1}$, enquanto as amostras de água subterrânea apresentaram valores diversos (entre $53 \mu \mathrm{S}$ $\mathrm{cm}^{-1}$ no PM-54 e $2678 \mu \mathrm{S} \mathrm{cm} \mathrm{cm}^{-1}$ no PM-40), indicando alteração na composição química da água e maior presença de sais dissolvidos no setor do PM40, situado em uma das áreas onde havia resíduos industriais enterrados.

$\mathrm{O}$ pH médio das águas do Rio Perequê $(6,65)$ e subterrâneas $(6,52)$ apresentou-se próximo à neutralidade. $\mathrm{O}$ Eh do Rio Perequê variou entre 130,80 e $-22,10 \mathrm{mV}$, característico de ambiente redutor, e entre $-270,30 \mathrm{mV}(\mathrm{PM}-20)$ e $143,40 \mathrm{mV}$ (PM-53) para a água subterrânea.

Na Tabela 9 são apresentados os resultados analíticos das amostras da água do Rio Perequê referentes a série nitrogenada. 
Tabela 9 - Resultados analíticos de série nitrogenada em água superficial $\left(\mathrm{mg} \mathrm{dm}^{-3}\right)$.

Table 9 - Analytical results of nitrogenous series in surficial water $\left(\mathrm{mg} \mathrm{dm}^{-3}\right)$.

\begin{tabular}{|c|c|c|c|c|c|}
\hline \multirow{4}{*}{$\begin{array}{l}\text { Parâmetros analisados } \\
\text { (mg/L) }\end{array}$} & \multicolumn{4}{|c|}{ Pontos de Amostragem } & \multirow{3}{*}{$\begin{array}{l}\text { Valores de Referên- } \\
\text { cia }\end{array}$} \\
\hline & \multicolumn{3}{|c|}{ Rio Perequê } & \multirow{3}{*}{ LQ } & \\
\hline & Montante & Central & Jusante & & \\
\hline & RP-01 & RP-02 & RP-03 & & CONAMA 357 \\
\hline Amônia como N & $<0,2$ & $<0,2$ & $<0,2$ & 0,2 & 3,7 \\
\hline Nitrogênio Kjeldahl Total & $<0,4$ & $<0,4$ & $<0,4$ & 0,4 & -- \\
\hline Nitrogênio Orgânico & $<0,4$ & $<0,4$ & $<0,4$ & 0,4 & -- \\
\hline Nitrato como N & 0,32 & $<0,3$ & 0,35 & 0,3 & 10 \\
\hline Nitrito como N & $<0,02$ & $<0,02$ & $<0,02$ & 0,02 & 1 \\
\hline
\end{tabular}

Não foram detectadas concentrações para amônia, nitrogênio Kjeldahl total, nitrogênio orgânico e nitrito. Para nitrato foram detectadas concentrações nas amostras a montante (RP-01) e jusante (RP-03), no entanto com valores bem inferiores ao limite da Resolução CONAMA 357 (BRASIL, 2005). Os dados da Tabela 9 mostram que a água do Rio Perequê não estava sendo afetada no período em que foi efetuada a amostragem, pela descarga procedente do aquífero livre da área de estudo.

Os resultados das análises químicas da água subterrânea (série nitrogenada) são apresentados na Tabela 10.

Tabela 10 - Resultados analíticos de série nitrogenada em água subterrânea $\left(\mathrm{mg} \mathrm{dm}^{-3}\right)$.

Table 10 - Analytical results of nitrogenous series in $\mathrm{m} \mathrm{dm}^{-3}$ (vales higher than CETESB limits are in blue).

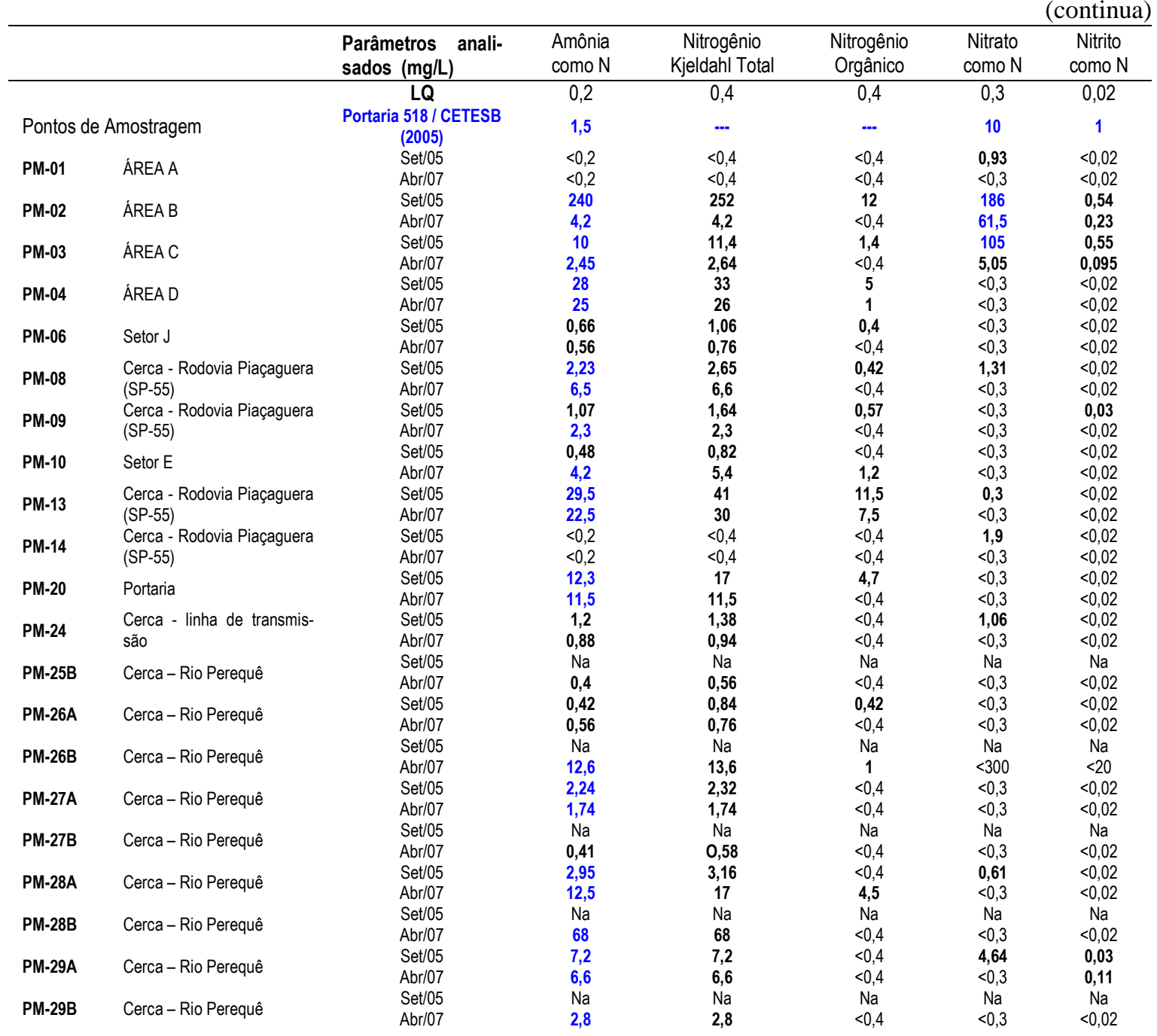


Tabela 10 - Resultados analíticos de série nitrogenada em água subterrânea $\left(\mathrm{mg} \mathrm{dm}^{-3}\right)$.

Table 10 - Analytical results of nitrogenous series in $\mathrm{mg} \mathrm{dm}^{-3}$ (vales higher than CETESB limits are in blue).

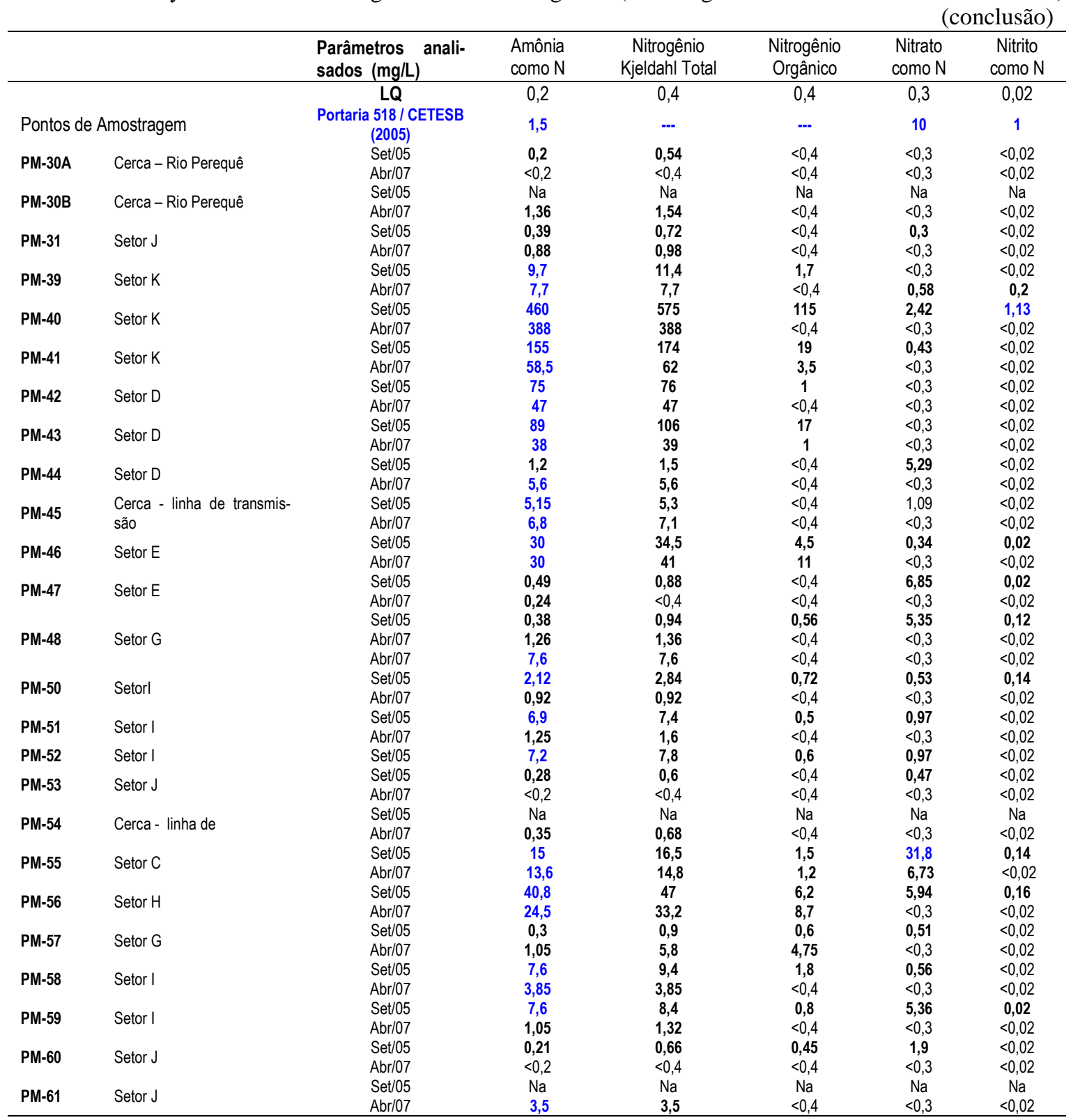

*Na - Não analisado.

A Amônia como $\mathrm{N}$ foi identificada em praticamente todos poços de monitoramento localizados nas Áreas B, C, D, E, F, H e K em concentrações acima do limite estabelecido pela Portaria 518 do Ministério da Saúde (1,5 mg/L), e em poços localizados nas áreas limítrofes do terreno (Rodovia Piaçaguera e Rio Perequê). A maior concentração foi verificada no PM-40, situado próximo ao local onde ocorreu a remoção de resíduo enterrado e armazenamento de matéria prima (uréia).

O Nitrogênio Orgânico, que é utilizado em fertilizantes, foi detectado em aproximadamente $20 \%$ dos poços monitorados, em concentrações que variaram entre $1 \mathrm{mg} / \mathrm{L}$ (PM-26B e PM-43) e $11 \mathrm{mg} / \mathrm{L}$ (PM-46). Não há valores de referência para este parâmetro bem como para o Nitrogênio
Kjeldahl Total (Amônia como $\mathrm{N}+$ Nitrogênio Orgânico).

O Nitrato como $\mathrm{N}$ foi detectado nos poços PM-02, PM-03 e PM-55, com concentrações acima do limite de intervenção da CETESB $(10 \mathrm{mg} / \mathrm{L})$, chegando a atingir $61,5 \mathrm{mg} / \mathrm{L}$ no $\mathrm{PM}-02$. O nitrito como $\mathrm{N}$ não foi identificado em concentrações acima dos limites de intervenção nos poços de monitoramento da área.

\section{Testes de permeabilidade}

A partir da média simples dos resultados obtidos nos poços indicados na Tabela 10 foi efetuada uma estimativa da condutividade hidráulica na área de estudo. A condutividade hidráulica média na área foi de $4,70 \times 10^{-4} \mathrm{~cm} / \mathrm{s}\left(10^{-5}-10^{-3}\right.$ 
$\mathrm{cm} / \mathrm{s}$ ). As observações de campo indicam que o solo é formado predominantemente por areia muito fina silto-argilosa, ou seja, predomínio da fração areia síltica.

\section{Modelagem matemática de fluxo e de transporte}

O modelo de fluxo foi desenvolvido considerando condição estacionária. Os vetores de direção indicaram que o fluxo segue em direção ao Rio Perequê (sentido oeste), com variações em função de particularidades da área. A Figura 3 indica as linhas equipotenciais e os vetores de direção do fluxo correspondentes à camada 1 .

As velocidades calculadas na área de estudo foram: $1,710^{-7} \mathrm{~m} / \mathrm{s}(5,36 \mathrm{~m} / \mathrm{ano})$ no setor montante e $6,810^{-7}(21,45 \mathrm{~m} / \mathrm{ano})$ na porção central. A máxima velocidade calculada foi de $1.3 .10^{-6} \mathrm{~m} / \mathrm{s}$ (41 m/ano), próximo à margem do Rio Perequê; contudo ressalta-se que este valor reflete a condição com maior declividade do terreno e influência do rio, não podendo ser estendida para toda a área.

Por apresentar concentrações acima da potabilidade e representatividade em área utilizou-se a amônia para simular a evolução das plumas de contaminação. Buscando avaliar a tendência de migração deste composto na área foram gerados caminhamentos de partículas a partir das fontes principais. Os principais mecanismos que afetam o transporte de solutos são: advecção, dispersão hidrodinâmica e sorção.

Foram utilizados os locais admitidos como representativos da fonte da pluma, as concentra- ções máximas observadas nos poços de monitoramento e a localização das fontes potenciais de contaminação, através da avaliação do histórico das concentrações de cada poço combinado ao procedimento de calibração do modelo.

O modelo conceitual da área (localização, extensão e intensidades das fontes e formas de disposição dos compostos) foi baseado em todas as informações disponíveis para gerar um modelo matemático válido (calibrado).

Foi considerado como tempo inicial a campanha de maio de 1997 e com o objetivo de avaliar riscos futuros associados a essa pluma os tempos de simulação se estenderam até 2027. Os dados calculados pelo modelo foram comparados com os resultados analíticos obtidos em todas as campanhas já existentes (1997 a 2007), excluindo os dados utilizados como representativos da fonte. Buscando a melhor calibração para o modelo foi avaliada a influência das concentrações iniciais, dispersão hidrodinâmica e sorção durante o processo da calibração.

Os resultados indicaram migração condicionada preferencialmente pelo fluxo, com sentido de evolução em direção ao Rio Perequê, sendo que a pluma delimitada para amônia como nitrogênio atinge o rio no tempo inicial em concentrações acima do limite de intervenção adotado.

A Figura 4 mostra a delimitação da pluma de amônia para o tempo inicial (abril de 2007) e as Figuras 5 e 6 ilustram a evolução da pluma em 10 e 20 anos. 


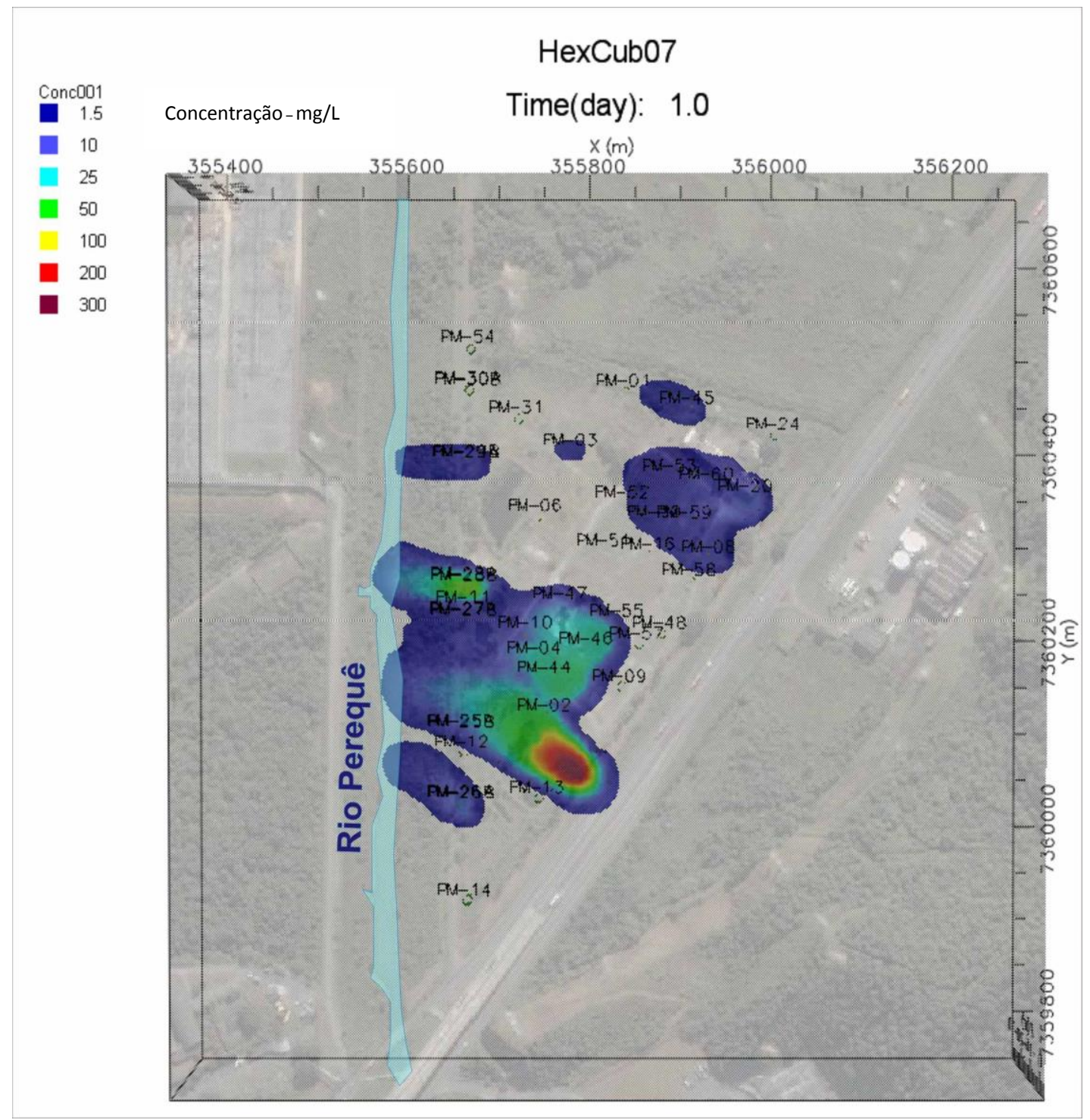

Figura 4 - Delimitação em planta da pluma de amônia (tempo atual). Figure 4 - Ammonium plume delimitation in plant (actual time). 


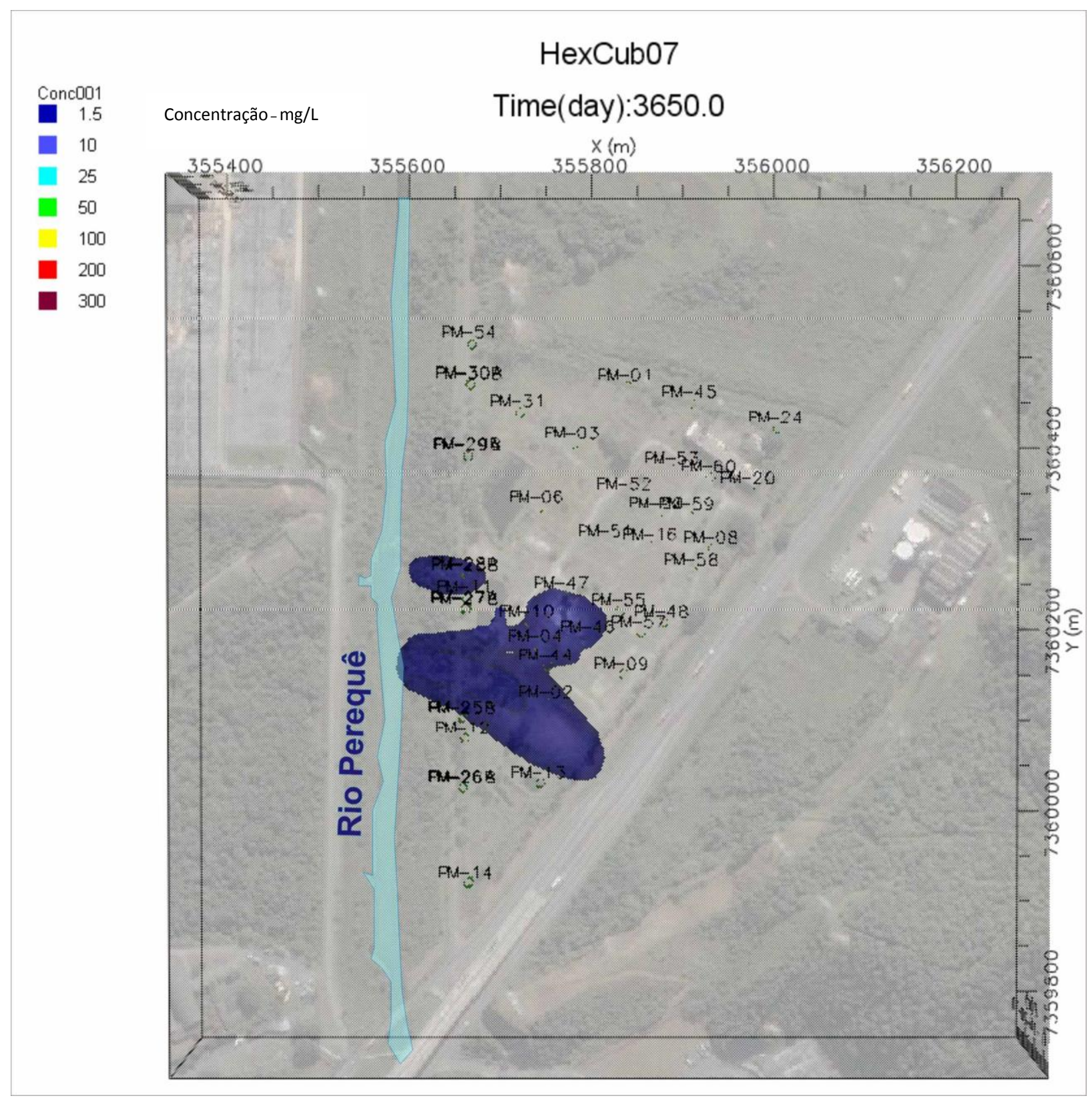

Figura 5 - Delimitação em planta da pluma de amônia (10 anos).

Figure 5 - Ammonium plume delimitation in plant (10 years). 


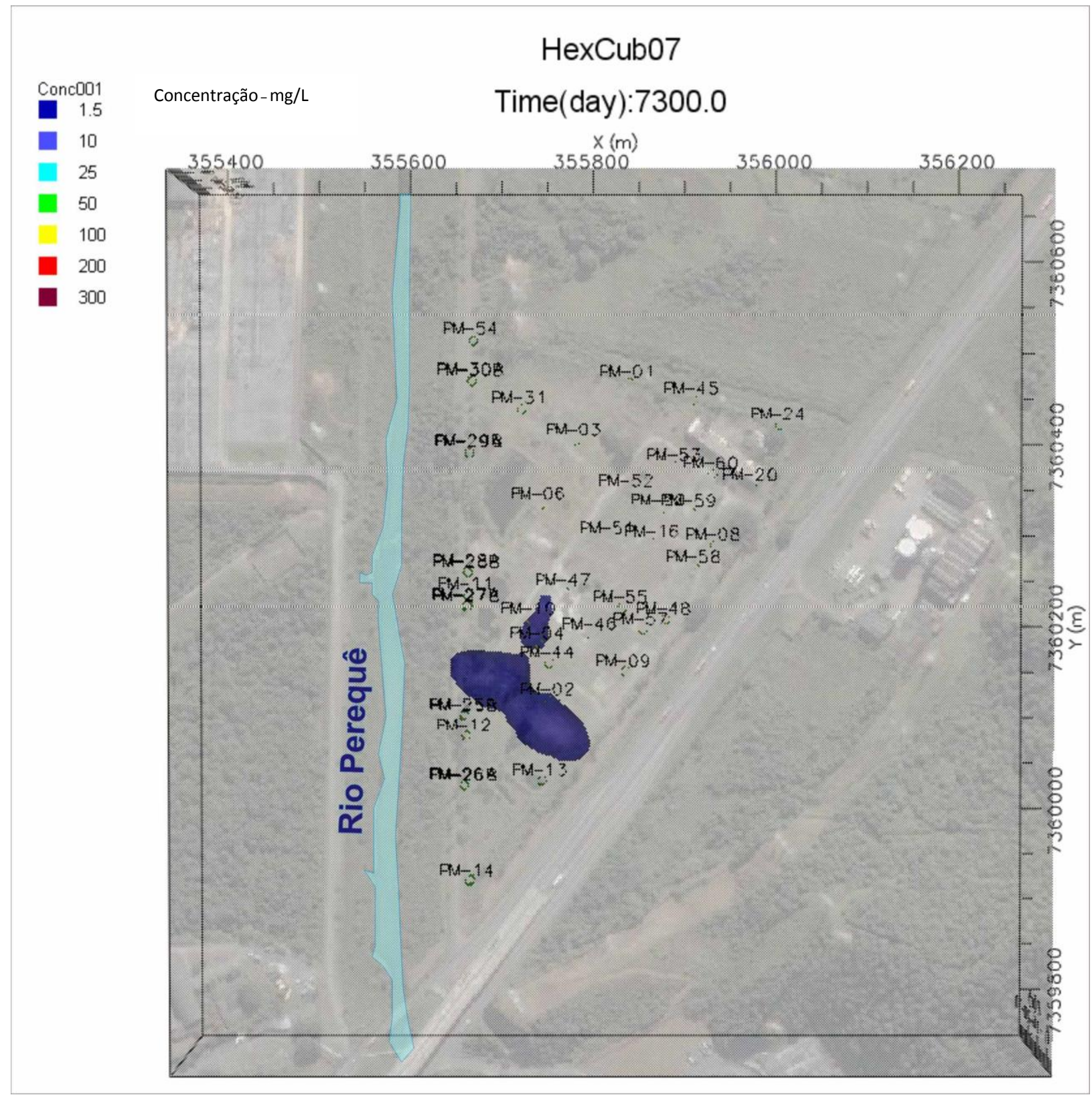

Figura 6 - Delimitação em planta da pluma de amônia (20 anos).

Figure 6 - Ammonium plume delimitation in plant (20 years). 
Os resultados, refletindo a premissa de fonte inativa, mostraram evolução da pluma com aumento da área atingida e migração do centro de massa com diminuição dos valores de concentração. O modelo indicou que em função da dimensão e dos níveis de concentrações observados a pluma ainda persiste ao final do período simulado, porém com concentração e área bem menores.

A delimitação da pluma em profundidade mostrou que a espessura atingida pela amônia foi relativamente pequena, restrita às partes superiores do modelo. Este comportamento era esperado, visto a distribuição da condutividade hidráulica em profundidade.

Os resultados da modelagem sugerem que o aporte de água com concentrações acima dos padrões adotados para amônia (Portaria 518 do Ministério da Saúde) do aquífero para o Rio Perequê tende a sofrer declínio até extinção num período de 10 anos, em função da configuração da pluma e velocidade do fluxo subterrâneo. Considerando o limite CONAMA para Classe 1 para águas doces, a pluma atinge o Rio Perequê com concentrações de amônia acima do valor estipulado (3,7 $\mathrm{mg} / \mathrm{L}$ ) nos 5 primeiros anos. A descarga inicial (considerando regime estacionário de fluxo) para frente da pluma é de $22 \mathrm{~m}^{3} / \mathrm{dia}$, e foi calculada baseando-se na condutância do rio.

Ressalta-se que nas amostras de água superficial do rio não foram detectadas concentrações acima dos padrões de referência. Com base neste controle pode-se afirmar que, embora haja um potencial para pluma atingir a drenagem superficial, a descarga gerada pelo aquífero não altera a qualidade do mesmo; esta condição pode estar correlacionada à capacidade de diluição do Rio Perequê.

Embora o valor de erro apresentado pela calibração seja inferior a 10\% (4,06\%), indicando a validade do modelo, a continuidade do monitoramento é recomendada para avaliar a evolução das concentrações.

\section{CONCLUSÕES E RECOMENDAÇÕES}

As análises químicas determinadas por Fluorescência de Raios X, assim como os resultados das extrações aquosas e nítricas indicam valores abaixo dos padrões de referência da CETESB para solos, confirmando que o comportamento iônico da área sofre pouca influência em relação aos atributos adsortivos do solo.

Nas Áreas B e C os valores de pH, condutividade elétrica e alcalinidade das águas subterrâneas apresentam anomalias como consequência do uso pretérito da área na qual se estocavam matéria prima de natureza orgânica, particularmente uréia.
Certamente ocorreram formações de compostos complexos estáveis que favoreceram eliminação dos íons do solo, com liberação para o aquífero livre.

As águas subterrâneas apresentam-se contaminadas com íons $\mathrm{Pb}$ e Ni ultrapassando os valores orientadores da CETESB. A presença dos íons $\mathrm{Al}$ e Fe na água subterrânea, por sua vez, apesar de valores de $\mathrm{pH}$ incompatíveis, pode estar associada às formas aquosas e livres como $\mathrm{Al}(\mathrm{OH})_{3} \mathrm{e}$ $\mathrm{Fe}(\mathrm{OH})_{3}$ e, possivelmente, ao elevado conteúdo iônico em solução. Não se descarta a hipótese da presença desses íons estar associada a formação de complexos orgânicos estáveis dada a natureza das atividades industriais das áreas com elevados teores de substâncias orgânicas.

Em boa parte dos poços de monitoramento foi identificada amônia em concentrações acima do limite de potabilidade. Cabe destacar que ela reage com a água subterrânea, formando cátions amônio, que pode competir com cátions em solução e sofrer adsorção junto às partículas do solo. Além de ser solúvel em água, o amônio é envolvido no processo biológico de fixação do nitrogênio, assim como na sua mineralização e nitrificação.

$\mathrm{O}$ nitrato, produto da ação de bactérias nitrificantes que agem sobre $\mathrm{o} \mathrm{NH}_{4}^{+}$, apresentou valores acima do limite de intervenção da CETESB em poços localizados nas Áreas B e C.

Baseando-se nos parâmetros físicoquímicos obtidos in situ, observa-se que a área de estudo ora se apresenta com características oxidantes, ora redutoras, responsáveis pela presença ou não de nitrato. A concentração de nitrito foi pouco significativa, por ser um ânion bastante instável que se oxida facilmente a nitrato.

O modelo matemático mostrou que o fluxo subterrâneo segue em direção ao Rio Perequê no sentido oeste. Considerando o limite CONAMA para águas doces, os resultados do modelo sugerem que o aporte de água com concentrações acima dos padrões adotados para amônia como nitrogênio, atinge o Rio Perequê acima do valor estipulado $(3,7 \mathrm{mg} / \mathrm{L})$ nos 5 primeiros anos, entretanto tende a sofrer declínio até extinção antes de passados 15 anos.

O impacto causado pelos íons metálicos pode ser remediado pela fixação de $\mathrm{Pb}$ e $\mathrm{Ni}$ nas formas sulfato e/ou óxidos/hidróxidos de chumbo e de hidróxidos de níquel. Maior atenção, no entanto, deve ser dada aos compostos nitrogenados que potencialmente se encontram disponíveis e migram em direção às drenagens.

Dentre as técnicas para remediar aquíferos contaminados com compostos nitrogenados e, levando em conta o custo/benefício de algumas de- 
las, podem ser recomendadas duas técnicas simultaneamente para acelerar o ciclo do nitrogênio. Primeiramente, através de poços de injeção, aplicando oxigênio e criando maior disponibilidade deste gás nas áreas com maior concentração de $\mathrm{NH}_{4}{ }^{+}$para estimular a formação de $\mathrm{NO}_{2}{ }^{-}$e $\mathrm{NO}_{3}{ }^{-}$. Posteriormente, a aplicação de uma fonte de carbono orgânico na água subterrânea pode estimular desenvolvimento de bactérias desnitrificantes para produzir nitrogênio. Outra técnica que poderia ser aplicada na área seria a instalação de barreira reativa no limite jusante da pluma, próximo ao Rio Perequê, com o propósito de induzir uma biorremediação sequencial de água subterrânea contaminada por amônio.

Para melhorar a eficiência da remediação,

\section{REFERÊNCIAS}

ASSOCIAÇÃO BRASILEIRA DE NORMAS TÉCNICAS ABNT. NBR 15495-1: Construção de poços de monitoramento e amostragem. Rio de Janeiro, 2007.

ASSOCIAÇÃO BRASILEIRA DE NORMAS TÉCNICAS ABNT. NBR 13895: Construção de poços de monitoramento e amostragem. Rio de Janeiro, 1997.

BRADY, N. C. Natureza e propriedades dos solos. 7. ed. Rio de Janeiro: Freitas Bastos, 1989.

BRASIL. Ministério da Saúde. Portaria n ${ }^{\circ} 518$ de 25 de março de 2004. Estabelece normas e o padrão de potabilidade da água destinada ao consumo humano. Diário Oficial da União, Brasília, v. 59, p. 266-270, 26 mar. 2004, Seção 1.

BRASIL. Ministério do Meio Ambiente/Conselho Nacional do Meio Ambiente. Resolução CONAMA n 357, de 17 de março de 2005. Dispõe sobre a classificação dos corpos de água e diretrizes ambientais para o seu enquadramento, bem como estabelece as condições e padrões de lançamento de efluentes, e dá outras providências. Diário Oficial da União, Brasília, no 53, p. 58-63, 18 mar. 2005, Seção 1.

BROOKINS, D.G. Eh - pH Diagrams for Geochemistry. New York: Springer-Verlag. 176 p., 1988.

CAMARGO, O. A.; MONIZ, A. C.; JORGE, J. A.; VALADARES, J. M. A. S. Métodos de análise química, mineralógica e física de solos do Instituto Agronômico de Campinas. Boletim Técnico. Campinas: Instituto Agronômico, 1986.

COMPANHIA DE TECNOLOGIA DE SANEAMENTO AMBIENTAL - CETESB. Manual de gerenciamento de áreas contaminadas. Projeto CETESB, GTZ. São Paulo, 389p., 2001.

COMPANHIA DE TECNOLOGIA DE SANEAMENTO AMBIENTAL - CETESB. Valores Orientadores para Solos e Águas Subterrâneas no Estado de São Paulo. São Paulo, levando em conta que o nível freático local é raso, poderia ser aplicada a técnica de fitoremediação em conjunto com as técnicas supracitadas, plantando-se espécies de raízes profundas.

Finalmente, se um possível aporte de compostos de nitrogênio estiver comprometendo a qualidade do Rio Perequê, a água subterrânea poderia ser removida utilizando poços de bombeamento instalados em linha (barreira hidráulica) no limite oeste da área e a água bombeada seria tratada por um sistema com wetlands instalado num dos reservatórios de água bruta e posteriormente descartada no rio. A viabilidade de aplicação destas técnicas dependerá de estudos detalhados sobre a influência das águas subterrâneas sobre as superficiais.

\section{CETESB, 2005.}

CONSULTORIA PAULISTA. Estudo de Impacto Ambiental - RIMA. Dragagem do Canal de Piaçaguera e Gerenciamento dos Passivos Ambientais. Cubatão/Santos - SP. Companhia Siderúrgica Paulista - COSIPA. 2004.

EMPRESA BRASILEIRA DE PESQUISA AGROPECUÁRIA - EMBRAPA. Manual de métodos de analise de solo. 2.ed. Rio de Janeiro: EMBRAPA - Centro Nacional de Pesquisa de Solos, 1997.

FERRER, L. M. Fixação e Mobilidade de Espécies de Mercúrio no Sistema Sedimento / Água do Mangue no Município de Cubatão, SP. São Paulo, 2001, 122 p. Dissertação de Mestrado. Instituto de Geociências - Universidade de São Paulo.

FETTER, C. W. Applied Hydrogeology. 4th ed. Upper Saddle River: Prentice-Hall, 598 p., 2001.

GARRELS, R.M.; CHRIST, C.L. Solutions, Minerals and Equilibria. New York: Harper \& Row, 1965.

HYPOLITO, R.; ANDRADE,S.; MARQUES, J.F.; NASCIMENTO, S.C.; EZAKI, S. Alcalinidade - Metodologia para Determinação em Campo. Analytica, v. 35, p. 52-61, 2008.

HYPOLITO, R.; ANDRADE,S.; EZAKI, S.; MARQUES, J.F.; NASCIMENTO, S.C. Método para Amostragem e Detecção de Íons em Águas da Zona Não Saturada. Analytica, v. 38, p. 85-92, 2009.

HYPOLITO, R.; ANDRADE,S.; EZAKI, S. Geoquímica da interação água/rocha/solo. Estudo Preliminares. São Paulo: All Print Editora, 450p., 2011.

INSTITUTO BRASILEIRO DE GEOGRAFIA E ESTATÍSTICA - IBGE. Censo Demográfico 2000: Anuário Estatístico do Brasil 2000. 2003. Disponível em: www.ibge.gov.br. 
INSTITUTO DE PESQUISA TECNOLÓGICA DO ESTADO DE SÃO PAULO - IPT. Texto Explicativo do Mapa Geológico do Estado de São Paulo, escala 1:500.000. São Paulo, Publicação IPT 1184, 1981.

KEENEY, D. Sources of nitrate to groundwater. CRC Critical Reviews in Environmental Control, v. 16, p. 257-304, 1989.

LOPES, A. S.; GUILHERME, L. R. G. Interpretação de analise de solo - Conceitos e Aplicações. Boletim Técnico ${ }^{\circ}$ 2. Associação Nacional para Difusão de Adubos, 36 p., 2004.

MARQUES, J. F. Comportamento de íons $\mathbf{P b}, \mathbf{Z n}, \mathrm{Cu}$ em área impactada por escória, produto da reciclagem de baterias chumbo-ácido. São Paulo, 2003. 120 p. Dissertação de Mestrado. Instituto de Geociências, Universidade de São Paulo.

MCDONALD, M.G.; HARBAUGH, A.W. A modular threedimensional finite-difference ground-water flow model: U.S. Geological Survey Techniques of Water-Resources Investigations, book 6, chap. A1, 586 p., 1988.

MEKARU, T., UEHARA, G. Soil Sci. Soc. Amer. Proc. Vol. 36, p. 296-300, 1972.

MONIZ, A.C. Elementos de Pedologia. São Paulo: Polígono, 459p., 1972.

OLIVEIRA, E. Contaminação de Aquíferos por Hidrocarbonetos Provenientes de Vazamentos de Tanques de Armazenamento Subterrâneo. São Paulo, 1992.112p. Dissertação de Mestrado. Instituto de Geociências, Universidade de São Paulo.

RAIJ, B. van; QUAGGIO, J. A.; CANTARELlA, H.;
FERREIRA, A. S. L.; BATAGLIA, O. C. Análise Química do Solo para Fins de Fertilidade. Campinas: Instituto Agronômico, 1987.

RAIJ, B. van; ANDRADE, J. C.; CANTARELlA, H.; QUAGGIO, J. A. Análise Química para avaliação de Fertilidade de Solos Tropicais. Campinas: Instituto Agronômico, 2001.

SHEPARD, F.P. Nomenclature based on sand-silt-clay ratios. Journal Sedimentary Petrology, v. 24, 151-158, 1954.

STUM, W.; MORGAN, J.J. Aquatic Chemistry. 2nd Ed. Toronto: John Wiley \& Sons, 1981.

SUTHERSAN, S. S. Remediation Engineering: Desing Concepts. Florida: Lewis Publishers, CRC press LLC, 362p., 1996.

TAN, K. H. Principles of Soil Chemistry. 2.ed. New York: Marcel Dekker, 1993.

TAKENO, N. Atlas of Eh-pH diagrams. Intercomparison of thermodynamic databases. National Institute of Advanced Industrial Science and Technology - Research Center for Deep Geological Environments. Geological Survey of Japan Open File Report No.419, 285p., 2005. Disponível em http://www.gsj.jp.

TORRES, F. R.; BRAGA, J. C. J.; BORGES, W. R. O que você precisa saber sobre Cubatão. Cubatão: Editora Design \& Print, 2002.

U.S. ENVIRONMENTAL PROTECTION AGENCY USEPA. Nitrogen Control Manual. Office of Research and Development. EPA/625/R93/010.1993. 